\title{
Intensification of the decadal activity in Equatorial Rossby Waves and linkage to changing tropical circulation
}

\author{
Wan-Ling Tseng ${ }^{1, *}$, S.-Y. Simon Wang ${ }^{2,3}$, Huang-Hsiung Hsu ${ }^{1}$, and Jonathan D.D. Meyer ${ }^{3}$ \\ ${ }^{1}$ Research Center for Environmental Changes, Academia Sinica, Taipei City, Taiwan \\ ${ }^{2}$ Department Plants, Soils and Climate, Utah State University, Logan, Utah, USA \\ ${ }^{3}$ Utah Climate Center, Utah State University, Logan, Utah, USA
}

\author{
Article history: \\ Received 17 August 2018 \\ Revised 10 December 2018 \\ Accepted 18 January 2019 \\ Keywords: \\ Equatorial Rossby waves, ERWs, \\ Wind shear, Walker circulation \\ Citation: \\ Tseng, W.-L., S.-Y. S. Wang, H.-H. \\ Hsu, and J. D. D. Meyer, 2019: In- \\ tensification of the decadal activity in \\ Equatorial Rossby Waves and linkage \\ to changing tropical circulation. Terr. \\ Atmos. Ocean. Sci., 30, 563-574, doi: \\ 10.3319/TAO.2019.01.18.02
}

\begin{abstract}
Equatorial Rossby waves (ERWs) are manifest as westward-propagating, planetary-scale waves that feature a symmetric pair of pressure and zonal wind fields about the equator. ERWs can modulate tropical convective activity, especially in South Asia and the Maritime Continents, and represent an important mode of intraseasonal variability additional to the Madden-Julian Oscillation. Changes in the frequency and intensity of ERWs during the recent decades were investigated based on observations of tropospheric winds and tropical convection. Spectral analyses indicated that ERWs appear to have intensified especially in the upper troposphere; this is associated with increased convective activity located off the equator. The strengthening and westward shift of the Walker circulation observed in the recent decades acted to increase the tropical vertical westerly shear and, subsequently, may contribute to the increased ERW activity. Further investigation on the dynamical process of the vertical zonal shear enhancement will improve the understanding of the changing ERW characteristics.
\end{abstract}

\section{INTRODUCTION}

In the tropical atmosphere, the equatorial Rossby waves (ERWs) describe a unique mode of planetary-scale waves with symmetric circulations to the north and south of the equator spanning $6000-18000 \mathrm{~km}$. The ERWs discussed here are part of the convectively-coupled equatorial waves that couple to moist convection and explain a large portion of the variance in tropical convection (Matsuno 1966; Wheeler and Kiladis 1999; Kiladis et al. 2009). In contrast with the predominant intraseasonal mode of the MaddenJulian Oscillation (MJO) that propagates eastward, ERWs move westward and have a phase speed of $5-10 \mathrm{~m} \mathrm{~s}^{-1}$ in the Pacific sector (Kiladis and Wheeler 1995). ERWs exhibit the highest variance in the Asian monsoon and warm pool regions (Kiladis et al. 2009) and can accompany the westerly wind burst events (Kiladis et al. 1994; Kiladis and Wheeler 1995). Figures 1a and b provide two examples of recent ERW episodes, portrayed in the Hovmöller diagrams

\footnotetext{
* Corresponding author

E-mail:wtseng@gate.sinica.edu.tw
}

of outgoing longwave radiation (OLR) anomalies averaged $5-20^{\circ} \mathrm{N}$ with a 5 -day running mean; one was in December 2014 and the other during December to January 2017. The 2014 episode coincided with the crash of AirAsia flight QZ8501, which encountered severe convective storms in the Maritime Continents prior to developing mechanical problems (BBC 2015a, b). The 2017 ERW episode led to southern Thailand's "worst rainfall in more than 30 years" (BBC 2015a, b; RTE 2017), submerging many villages (BBC 2017). These events illustrate ERWs' potential in producing life-altering weather extremes. Some studies suggested that ERWs are also capable of initiating the MJO under certain conditions (Wang and Xie 1996; Meehl et al. 2001; Roundy and Frank 2004; Weickmann and Berry 2007).

There are reasons to suspect that ERWs may be modified by the observed changes in the tropical circulations. Theoretical studies (Zhang and Webster 1989; Wang and Xie 1996; Xie and Wang 1996) indicate that the strengthened vertical shear and intensified heating can lead to unstable ERWs with increased baroclinic growth. These conditions coincide with 
the intensification in vertical zonal wind shear observed during the past few decades, given that the tropical atmospheric circulations has seen a strengthening of the Walker circulation (Meng et al. 2012; L'Heureux et al. 2013; Thompson et al. 2015; Ma and Zhou 2016).

In this paper, we examine the interdecadal variation in ERWs based on diagnosis of observational data while validating the previous derivations of the mean flow impact on ERWs. Theoretical derivations of ERWs and their interaction with the mean circulation have been explored extensively (Wang and Xie 1996; Xie and Wang 1996), while the MJO's observed and projected changes have been examined by a number of studies (Maloney and Xie 2013; Arnold et al. 2015; Chang et al. 2015). The ERW's activity has been linked to large-scale climate modes like the two types of ENSO, as well as the monsoon variability (Takayabu and Nitta 1993; Kug et al. 2009). Therefore, analytical solutions, the $\mathrm{MJO} /$ Kelvin Wave linkage, and the interannual variability are not our focus here. Instead, the paper was focused on examining the extent to which ERWs have changed in the recent decades under the strengthened vertical shear environment, using common spectral analysis methods. The data and methods used to extract ERWs are explained in section 2 , followed by discussion of the results in section 3 and some conclusions in section 4.

\section{DATA AND ERW EXTRACTION}

\subsection{Data}

To depict the tropical convective activity, we used daily OLR data retrieved from the High Resolution Infrared Radiation Sounder (HIRS) radiance observations onboard satellites with a $1^{\circ} \times 1^{\circ}$ resolution (Ellingson et al. 1989; Lee et al. 2007; Lee 2014). Differences in the atmospheric circulations were derived from two modern-era reanalysis datasets: the ERA-interim reanalysis (Dee et al. 2011) and the Japan Meteorological Agency reanalysis JRA-55 (Ebita et al. 2011; Harada et al. 2016) beginning in 1979. For longer-term analysis, we used the NCEP/NCAR Reanalysis and NOAA's 20th-Century Reanalyses that begins in 1948 and 1871, respectively (Kalnay et al. 1996; Compo et al. 2006). We also analyzed the new Precipitation Estimation from Remotely Sensed Information using Artificial Neural Networks (PERSIANN) providing daily $0.25^{\circ}$-resolution precipitation since 1983 (Sorooshian et al. 2014; Ashouri et al. 2015).

\subsection{Method}

Extraction of ERWs from the wind and OLR datasets was applied with the space-time bandpass filter at each data (a) $\triangle O L R$

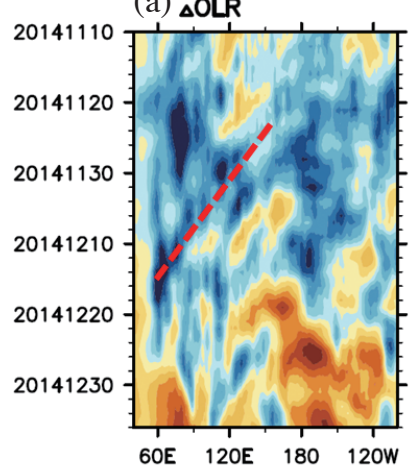

(b) $\triangle O L R$

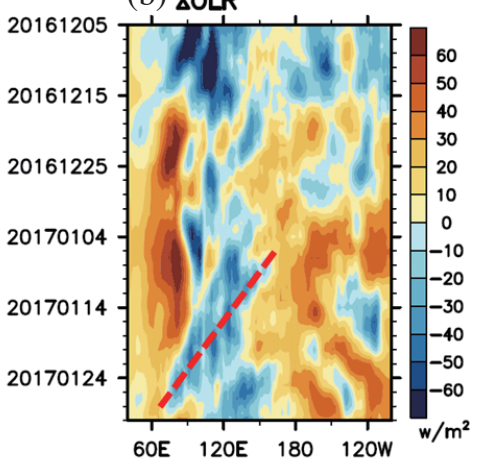

(c) Vertical westerly shear

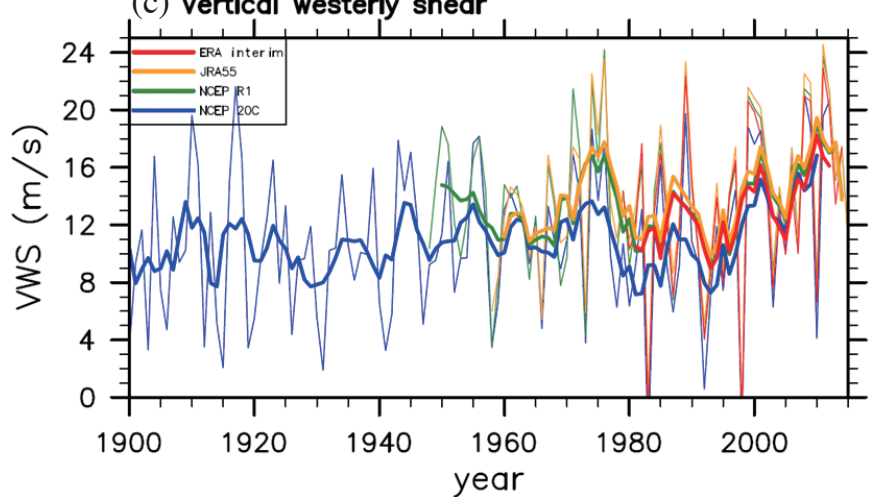

Fig. 1. (a) (b) Hovmöller diagram of 5-days-running mean OLR ( $\left.\mathrm{W} \mathrm{m}^{-2}\right)$ anomalies averaged $5-20^{\circ} \mathrm{N}$. The red line indicates the ERWs events. (c) The DJF zonal wind shear (U250 - U850; averaged $\left.5^{\circ} \mathrm{S}-5^{\circ} \mathrm{N}, 160^{\circ} \mathrm{E}-120^{\circ} \mathrm{W}\right)$. The thin line denotes the raw values, while the thick line depict the low pass filtered (applying a 5-year-running mean) time series. Units: $\mathrm{m} \mathrm{s}^{-1}$. 
point, following the common spectral analysis for tropical intraseasonal variability developed by Wheeler and Kiladis (1999) and Kiladis et al. (2006). Here, ERWs were obtained by filtering (extracting) the westward component of zonal wavenumber $1-8$, with equivalent depth of $8-90 \mathrm{~m}$ and frequency of $1 / 10$ to $1 / 90$ cycle per day as resolved from the filtering. Symmetricity is crucial in the definition of ERWs (Kiladis and Wheeler 1995; Wheeler et al. 2000; Straub and Kiladis 2002); thus, the symmetric component of a variable $F$ is defined as $F s(\varnothing)=[F(\varnothing)+F(-\varnothing)] / 2$, where $\varnothing$ is latitude. The variances of the OLR and winds were then computed from the filtered data. We also computed the wavenumberfrequency spectra of the selected variables by following the methods used in Hayashi (1971) and Wheeler and Kiladis (1999). ERWs are most active during the boreal winter (Wheeler et al. 2000); thus, the present analysis was focused on December, January, and February (DJF).

\section{RESULTS}

The notion that the vertical westerly shear has increased over the past century is illustrated in Fig. 1c, defined by the zonal wind difference between the upper $(200-\mathrm{hPa})$ and lower $(850-\mathrm{hPa})$ atmosphere averaged over the climatological Walker Circulation region in the tropical Central Pacific $\left(160^{\circ} \mathrm{E}-120^{\circ} \mathrm{W}, 5^{\circ} \mathrm{S}-5^{\circ} \mathrm{N}\right)(\mathrm{Ma}$ and Zhou 2016). The vertical wind shear reveals a strengthening tendency that persisted into the early $21^{\text {st }}$ century and this trend is consistent among the different reanalysis datasets. Numerous studies have attributed this recent strengthening in the tropical zonal circulation to both internal variability and global warming, with the latter being linked to a La Niñalike pattern (Funk and Hoell 2015; Li et al. 2016) and/or a stronger Walker circulation (Hsu and Chen 2011; Meng et al. 2012; L'Heureux et al. 2013; Thompson et al. 2015; Ma and Zhou 2016). The ensuing analysis was based upon such aforementioned changes in the tropical circulation but it does not necessarily imply any future trend.

\subsection{Interdecadal Variation in ERW-Related Convective Activity}

Analytical solutions obtained by Wang and Xie (1996) have indicated that an increase in the background vertical westerly shear should enhance positive vorticity manifested as westward propagating equatorial waves (i.e., barotropic and baroclinic ERWs). To examine this, we computed the ERW component of daily OLR variance following the filtering method described in section 2.2. Figure 2 shows the horizontal distribution of the OLR variance representing ERWs over the DJF of two eras: (a) 1979 - 1997, (b) 1998 2015 , and (c) their era-difference. The two era-difference is not sensitive to the time periods chosen (not shown) and the year 1997 only reflects the midpoint of available modern- reanalysis data.

In Fig. 2, the maximum variance is located off the equator over the Western Pacific around $12^{\circ} \mathrm{S}$ and $12^{\circ} \mathrm{N}$; this is consistent with the climatological maximum of ERW-related convective activity (Wheeler and Kiladis 1999; Wheeler et al. 2000). In the era-difference, the OLR variance did increase over the east Indian Ocean subtropics, and the increases are significant at the $5 \%$ level. The ratio of ERWs variance and total variance is $9.0 \%$ during (a) 1979 1997 and $9.6 \%$ during the (b) 1998 - 2015. For verification purposes, a separate set of analysis without decomposition of ERWs into the symmetric component about the equator is shown in Fig. 3, revealing the full signal of the waves; this result suggests a similar and even stronger enhancement of the westward-propagating tropical waves. Further examination of the interdecadal variation in OLR variances in other seasons (Fig. 4) shows a relatively stronger enhancement in spring and summer with a slight weakening in fall.

The regional features of the OLR spectra between the different eras were computed from each of the zonal wavenumber within the symmetric $5-20^{\circ}$ zone and displayed in Figs. 2d - f, showing only the westward propagation component. The increased OLR variance across the ERW spectrum is apparent and it suggests an enhancement of the convective activity off the equator. To quantify such an enhancement, we integrated zonal wavenumbers 2 - 5 (i.e., the dominant ERW wavelength) in the periods of 20 - 50 days, yielding an increase in the ERW amplitude of $\sim 11 \%$ with a peak period of 25 days, after 1998.

We note that the satellite-derived OLR may include bias resulted from orbital degradation; therefore, the PERSIANN precipitation was also examined and the result (Fig. 5) shows a similar interdecadal variation in the ERWregime precipitation with that of the OLR. Given the possibility that tropical atmospheric humidity and cloudiness can influence the change in OLR/precipitation variances, we further computed the apparent heat source term based upon the derivation of Yanai et al. (1973), commonly known as "Q1" [Eq. (8) in Yanai et al. 1973]. The variance of the 1000 - $200 \mathrm{hPa}$ integrated Q1 within the ERW spectral regime (Fig. 6) also shows a robust increase, supporting the OLR and precipitation analyses.

\subsection{Vertical Wind Shear}

ERWs are more strongly affected by vertical shear than other convectively coupled waves (Dias and Kiladis 2014). To examine the kinematic property of the ERW's interdecadal variation, we analyzed the 250 -hPa zonal wind variance derived from the ERA-interim reanalysis (Figs. 7a and b). The era-difference of the zonal wind's variance reveals a clear enhancement in the ERW regime along the equator (Fig. 7c), with particularly strong increases across the tropical Pacific and the Indian Ocean (significant at the 5\% 
interval). We should note that, within an ERW, convection responds to the two cyclonic circulations so the maximum OLR would be located off the equator while the maximal zonal wind would appear along the equator. By averaging the zonal wind within the equatorial band from $10^{\circ} \mathrm{S}-10^{\circ} \mathrm{N}$, the spectral analysis (Figs. 7d - f) shows a $17.5 \%$ increase in wavenumbers $2-5$ within the period of $20-50$ days. This spectral coherence between OLR and zonal winds lends support to the theoretically derived property change in ERWs in response to increased vertical westerly shear. As further examination, we computed the $250-\mathrm{hPa}$ meridional wind variance and associated changes by following Kiladis and Wheeler (1995); the result (Fig. S1) also indicates a consistent increase in ERWs in the central east Pacific.

Theoretical studies (Wang and Xie 1996; Xie and Wang 1996) predict an upper-level enhancement of ERWs under increased vertical westerly shear. For heating-induced internal ERWs, vertically sheared zonal flow plays an es- sential role in the emanation of ERWs into the extratropics; this is because easterly (westerly) shears tend to confine the unstable equatorial waves in the lower (upper) troposphere. Based on these previous findings, the interdecadal variation in the vertical structure of ERWs was examined by averaging the zonal wind variance within the tropical Pacific $\left(160^{\circ} \mathrm{E}\right.$ $-120^{\circ} \mathrm{W}$; Fig. 8b) along with their era-difference (Fig. 8a). The largest increase in the ERW's zonal wind variance is located on the equator centered around $200-\mathrm{hPa}$. The magnitude of the increase appears to weaken substantially towards the surface. Compared to the climatological distribution of the ERW wind variance (Figs. 8a and b), the ERW activity has apparently moved closer to the equator while becoming more equatorially trapped (i.e., narrower and stronger). In the case of vertical westerly shear, both the barotropic and baroclinic modes of ERWs tend to be in phase (Wang and Xie 1996) and this causes the perturbation's confinement to the upper troposphere, supporting Fig. 8a.

\section{OLR ERWs variance}

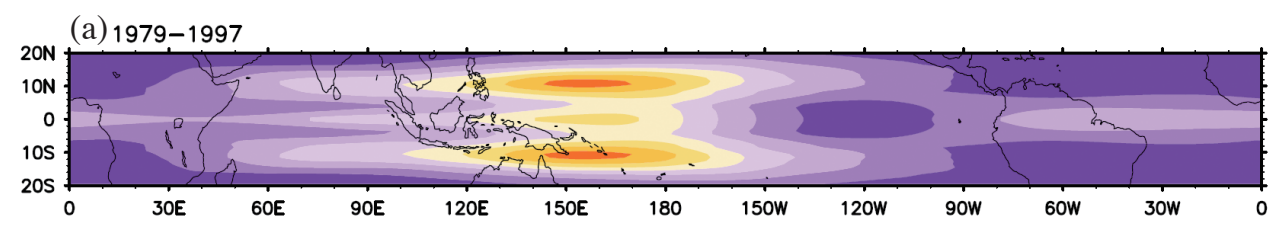

(b) $1998-2015$
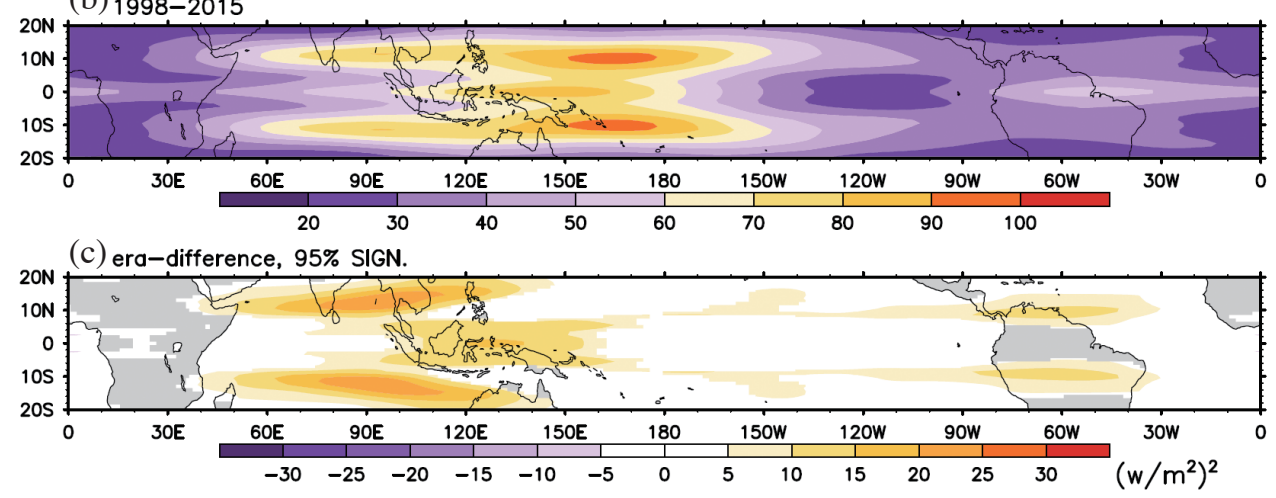

\section{OLR spectra}

(d) $1979-1997$

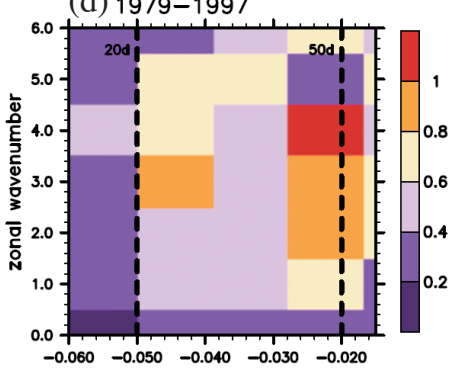

(e) 1998-2015

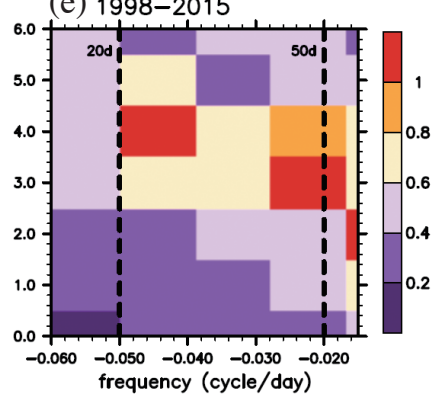

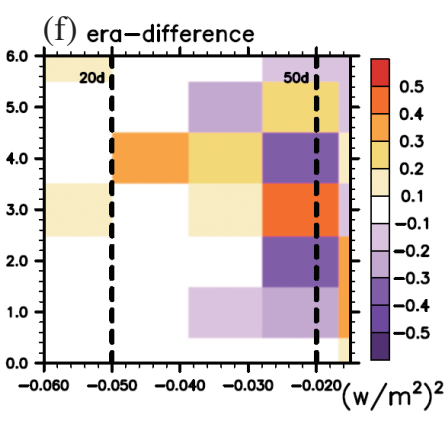

Fig. 2. Upper panel is the DJF ERWs filtered variance of the OLR (unit: $w m^{-2}$ ) over (a) 1979 - 1997 and (b) 1998 - 2015. (c) is the era-difference between (b) and (a) to indicate interdecadal variation. The filtered method is described in the section 2.2. Only $95 \%$ significant value is shown. Bottom panel is the symmetric $5-20^{\circ}$ averaged wavenumber-frequency spectra for equatorial OLR by (d) 1979 - 1997, (e) 1998 - 2015, and (f) the era-difference between (e) and (d). 


\section{OLR ERWs variance}

(a) $1979-1997$

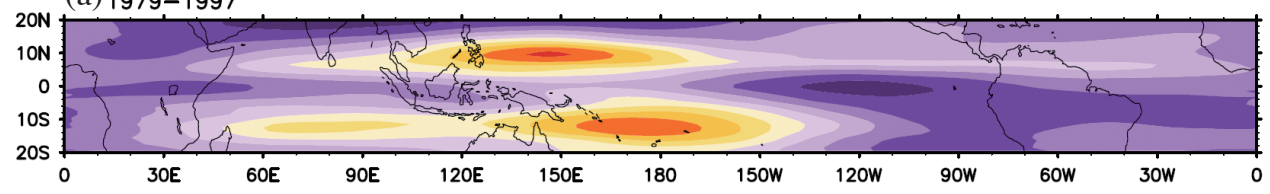

(b) $1998-2015$
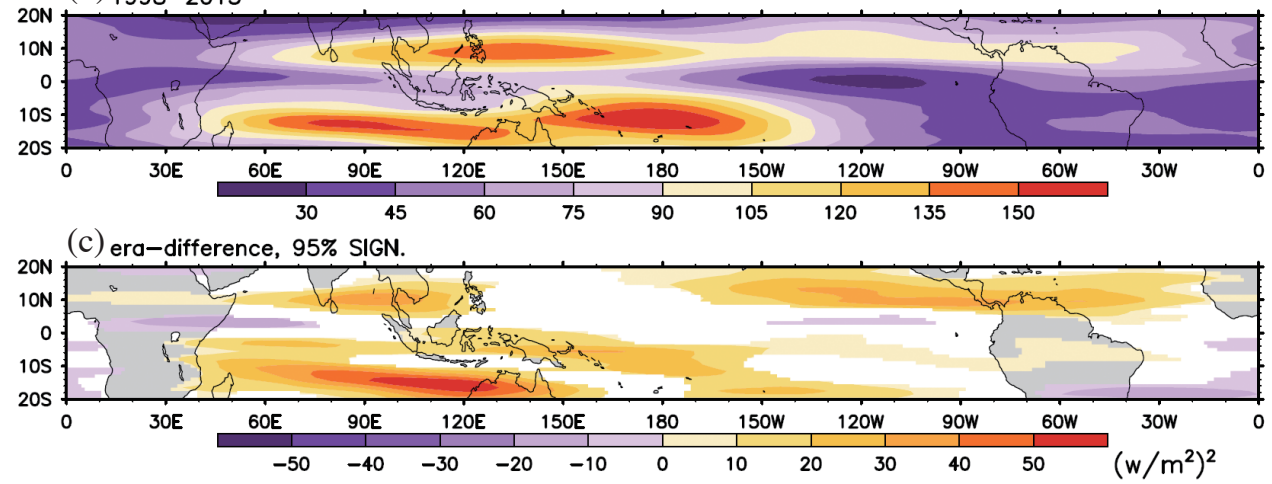

\section{OLR spectra}

(d) 1979-1997

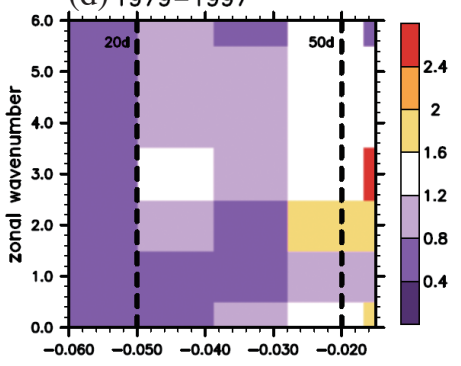

(e) 1998-2015

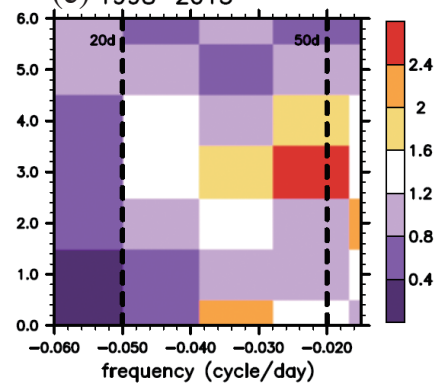

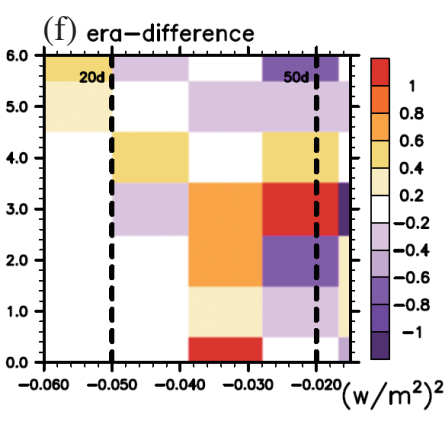

Fig. 3. Same as Fig. 2c, but without first decomposing into symmetric components about the equator.

(a) MAM

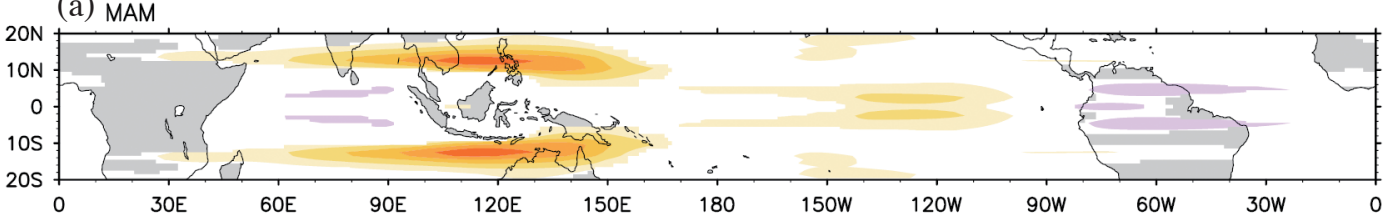

(b) JJA

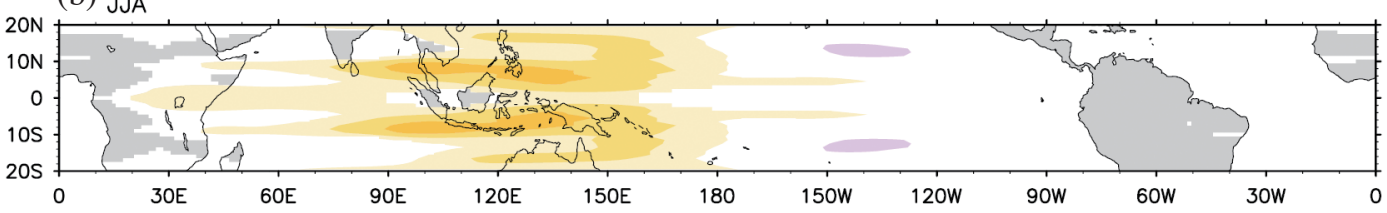

(c) SON

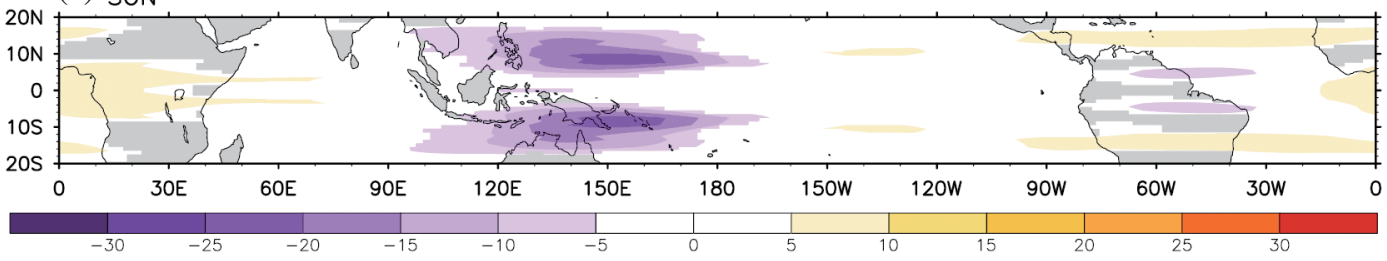

Fig. 4. Same as Fig. 2c, but in different seasons follow by (a) MAM, (b) JJA, and (c) SON. 


\section{Precipitation ERWs variance}

(a) 1983-1997

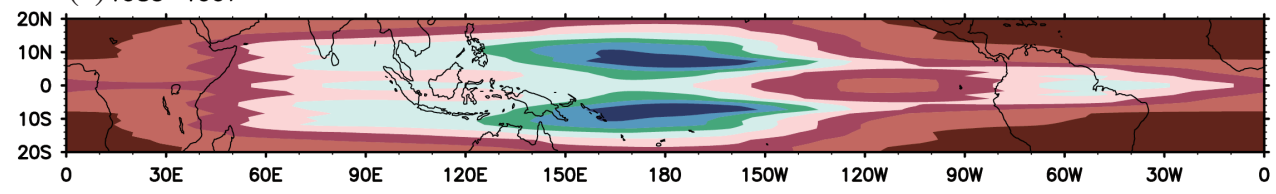

(b) 1998-2015

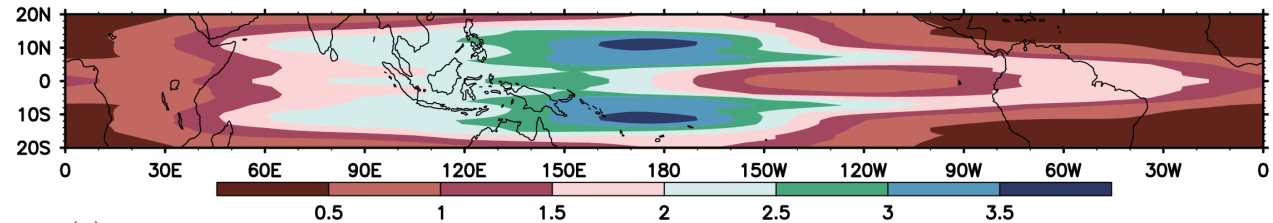

(c) era-difference, $95 \%$ SIGN.

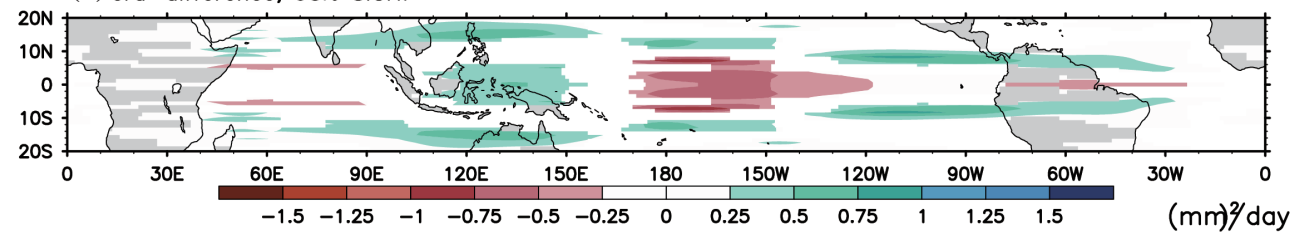

\section{Precipitation spectra}

(d) 1983-1997

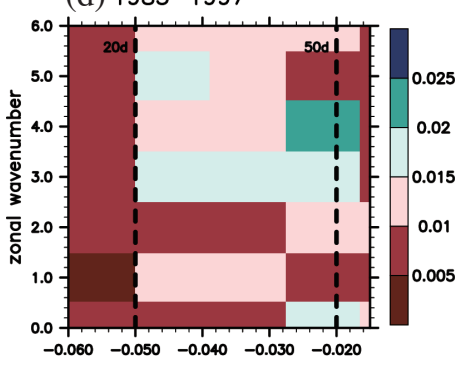

(e) 1998-2015

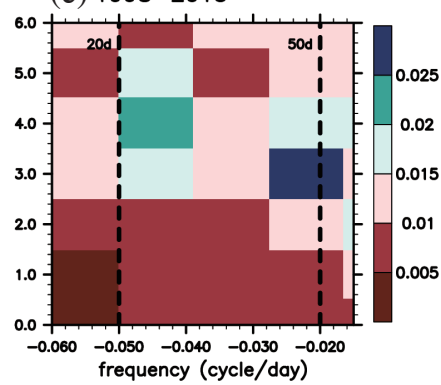

(f) era-difference

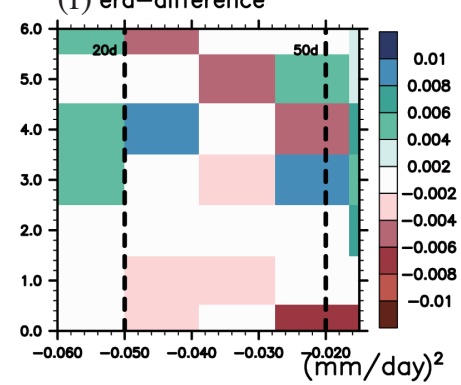

Fig. 5. Same as Fig. 2, but PERSIANN precipitation (unit: $\mathrm{mm} \mathrm{day}^{-1}$ ). (d) - (f) are averaged by symmetric $5-20^{\circ}$. 


\section{Q1 1000-200hPa ERWs variance}

(a) $1979-1997$

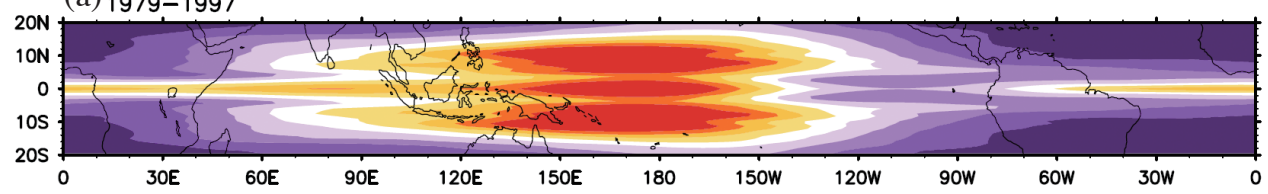

(b) $1998-2015$
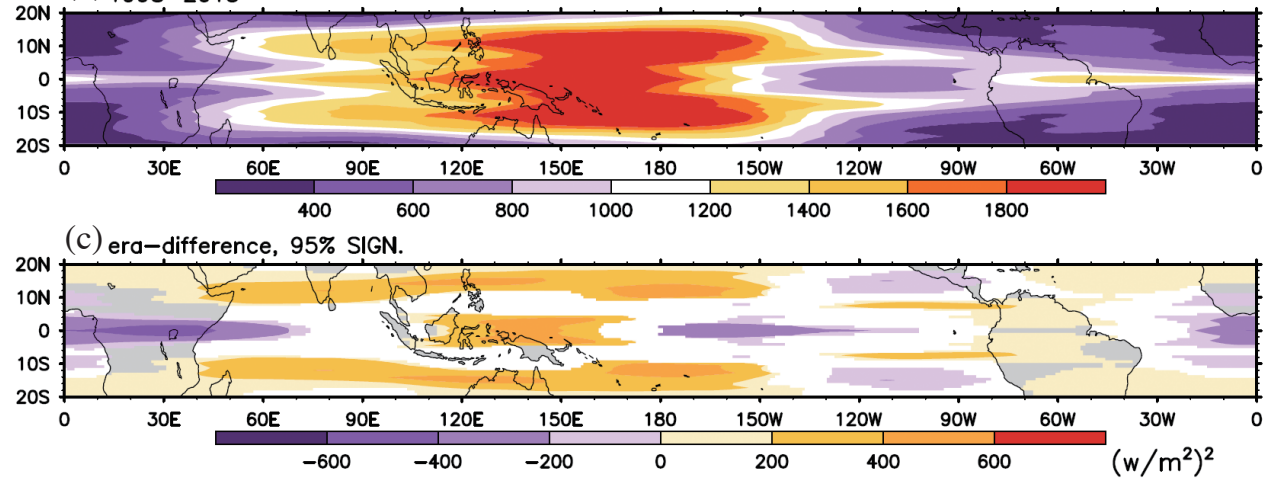

\section{Q1 1000-200hPa spectra}
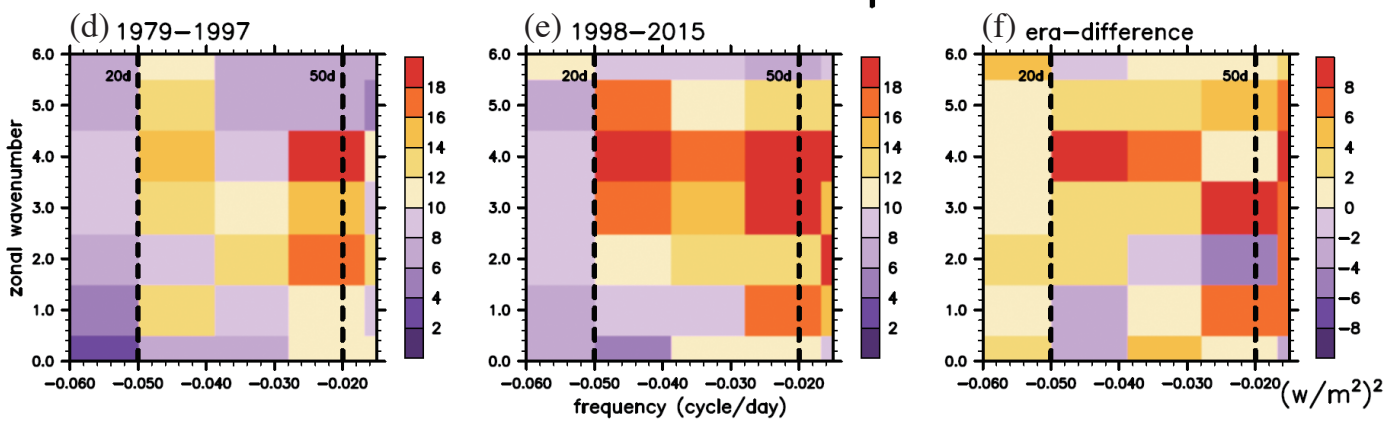

Fig. 6. Same as Fig. 2, but integrated Q1 from 1000 - $200 \mathrm{hPa}$ (unit: $\mathrm{w} \mathrm{m}^{-2}$ ). (d) - (f) are averaged by symmetric $5-15^{\circ}$. 


\section{0hPa zonal wind ERWs variance}

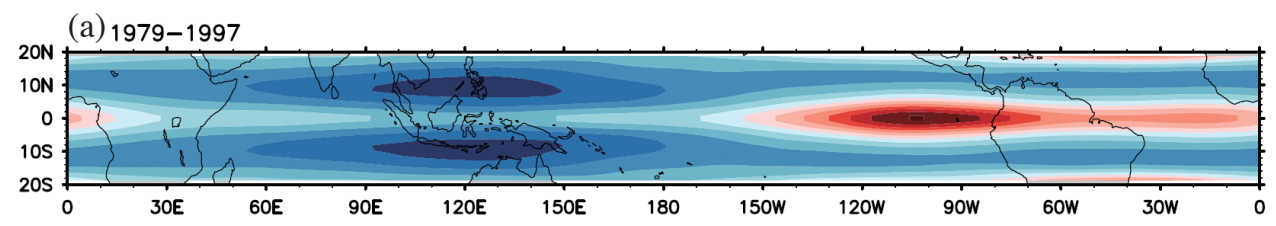

(b) 1998-2015

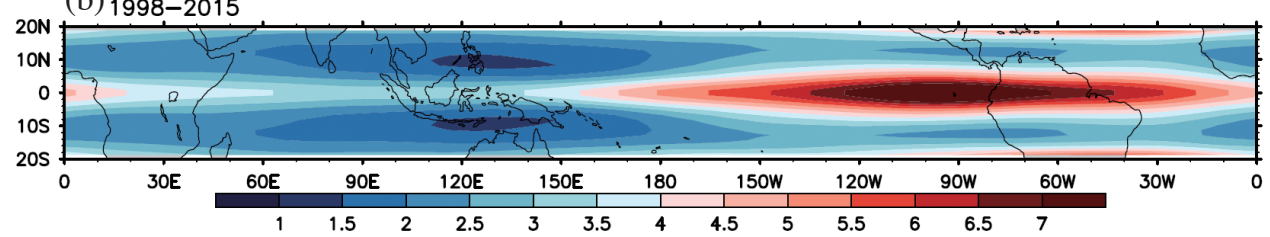

(c) era-difference, $95 \%$ SIGN.

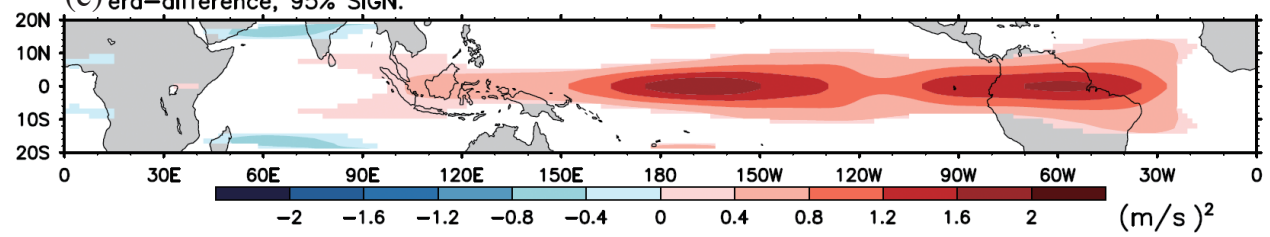

\section{$250 \mathrm{hPa}$ zonal wind spectra}

(d) 1979-1997

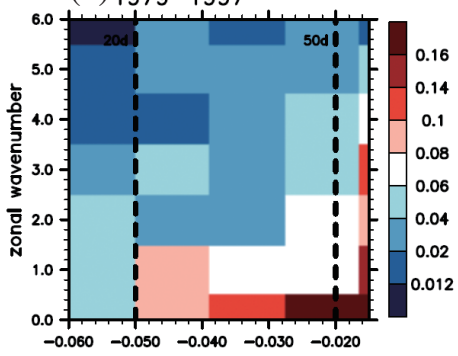

(e) $1998-2015$

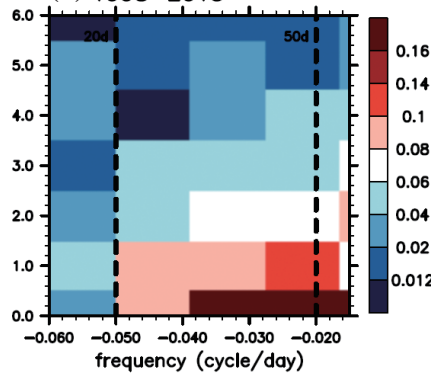

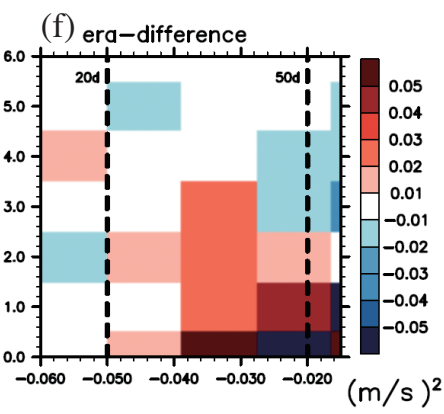

Fig. 7. Same as Fig. 2, but $250 \mathrm{hPa}$ zonal wind (unit: $\mathrm{m} \mathrm{s}^{-1}$ ). (d) - (f) are averaged by symmetric $10^{\circ} \mathrm{S}-10^{\circ} \mathrm{N}$.

(a) ERWs variance

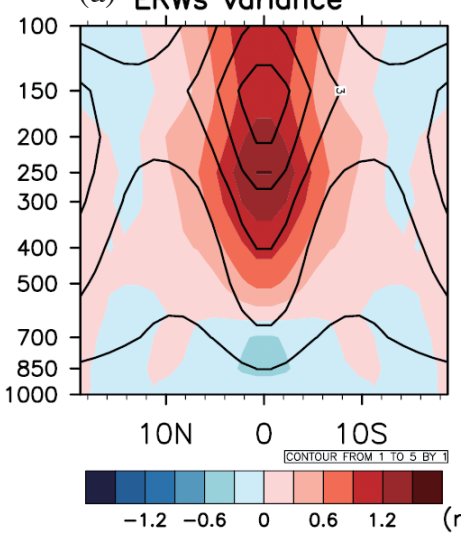

(b) Vertical westerly shear v.s. ERWs variance

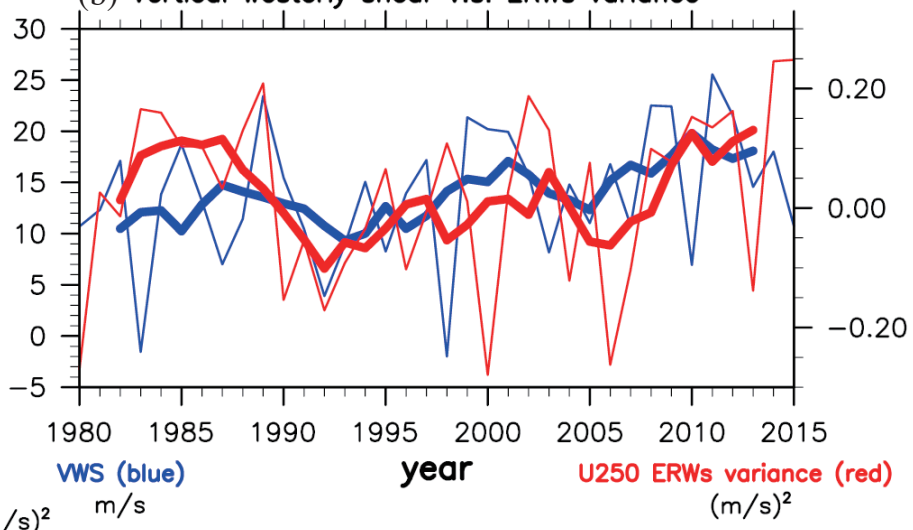

Fig. 8. (a) The DJF $160^{\circ} \mathrm{E}-120^{\circ} \mathrm{W}$ averaged era-difference ERWs filtered variance of the zonal wind (unit: $\left.\mathrm{m}^{2} \mathrm{~s}^{-2}\right)$ over (1998 - 2015) minus (1979 - 1997) to illustrate interdecadal variation. Contours are the same but climatology (1979 - 2015). (b) The DJF interannual variability of the wind shear (blue: $\mathrm{m} \mathrm{s}^{-1}$ ) and U250 ERW variance $\left(\right.$ red: $\mathrm{m}^{2} \mathrm{~s}^{-2}$ ) averaged over symmetric $5^{\circ} \mathrm{S}-5^{\circ} \mathrm{N}, 160^{\circ} \mathrm{E}-120^{\circ} \mathrm{W}$. The thin line denotes the raw values, while the thick line depict the low pass filtered (applying a 5-year-running mean) time series. 
By computing the correlation between the vertical westerly shear and the ERW zonal wind variance (Fig. 8b), their correspondence appears weak and insignificant. However, a correspondence did exist between their low-frequency variations (with the 5-year running means) showing a correlation coefficient of 0.4 ; this is significant at a $10 \%$ confidence level after accounting for the reduced degree of freedom. Further examination of the vertical structure of the ERWs variance, following Fig. 8a, is shown in Fig. 9 by averaging at every $30^{\circ}$ longitude from $60^{\circ} \mathrm{E}-120^{\circ} \mathrm{W}$. The vertical wind shear along the equator at each longitudinal sector (averaged $5^{\circ} \mathrm{S}$ $5^{\circ} \mathrm{N}$ ) is plotted in Fig. 9b showing its long-term mean (blue) and era-difference (red). A pronounced increase occurs in the upper- and mid-level ERW variance and this is within the westerly shear regime (east of $150^{\circ} \mathrm{E}$ ). We note that vertical easterly shear, which can confine ERWs in the lower troposphere (Wang and Xie 1996; Xie and Wang 1996), also shows an interdecadal variation in some areas. Despite the seemingly universal increase in the upper-level ERW variance, the more confinement of ERWs in the lower level (between 500 and $700-\mathrm{hPa}$ ) did occur alongside the increasingly easterly shear regime (west of $150^{\circ} \mathrm{E}$ ).

\section{CONCLUSIONS}

This study investigated interdecadal variations in the ERW activity from satellite and reanalysis data. The results suggest that the variance and power spectra of OLR, precipitation and wind fields within the ERW regime have increased in recent decades. This observation supports the theoretically derived enhancement (and trapping) of ERWs, given that the equatorial transient kinetic energy and the upper-level zonal flow tend to be in-phase under vertical westerly shear (Murakami and Unninayar 1977; Arkin and Webster 1985). Furthermore, the main increase in the OLR spectra variance occurred to the north of the equator (around $12^{\circ} \mathrm{N}$ ) associated with the overall increase of $250 \mathrm{hPa}$ zonal wind spectra variance along the equatorial Pacific and Indian Ocean. The strengthening of ERWs in the upper troposphere corresponds to the predominant vertical westerly shear, while minor increases in the lower troposphere respond to the relatively stronger easterly shear over the IndoPacific warm pool. Increased ERW activities also imply a subsequent increase in the tropical subseasonal variability, which may accompany and complicate the projection of the MJO magnitude (Maloney and Xie 2013; Arnold et al. 2015; Chang et al. 2015).

These results do not suggest that the vertical shear is the only reason for the enhancements in ERWs and associated convection. Further analysis with coupled-model simulation is needed in order to attribute the roles both the sea surface temperature and the atmospheric thermodynamics play, though current model performance on ERWs is questionable. Likewise, ERWs can also be forced by wave energy originating in the extratropics (Kiladis and Wheeler 1995; Kiladis 1998; Hoskins and Yang 2000; Yang et al. 2007; Kiladis et al.2009) where the circulation in recent years has profoundly changed. Future investigation on the dynamical process of the observed vertical zonal shear enhancement, as well as the role of multidecadal variability, will improve the understanding of the changing ERW characteristics.

Acknowledgements This study was supported by the Ministry of Science and Technology, Taiwan MOST 107-2119-M-001-010. Partial support for WLT's research visit by D.J. Wang led to this study and is highly appreciated. Interpolated OLR data and NCEP Reanalysis data are provided by the NOAA/OAR/ESRL PSD, Boulder, Colorado, USA, from their Web site at http://www. esrl.noaa.gov/psd/. The ERA-interim reanalysis, Japan Meteorological Agency reanalysis JRA-55 and Precipitation Estimation from Remotely Sensed Information using
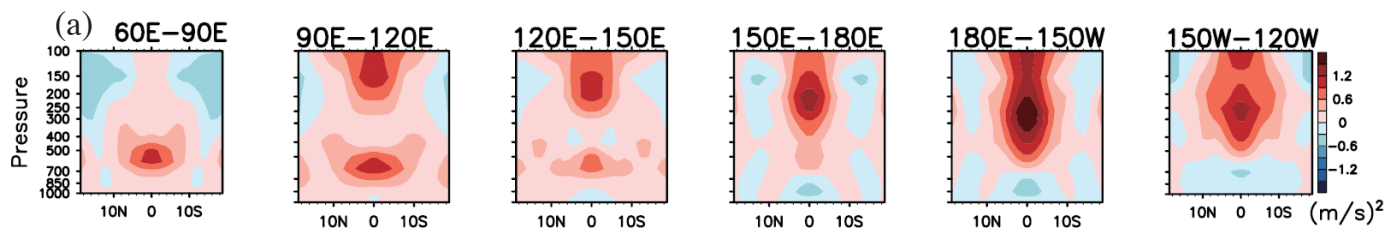

(b)

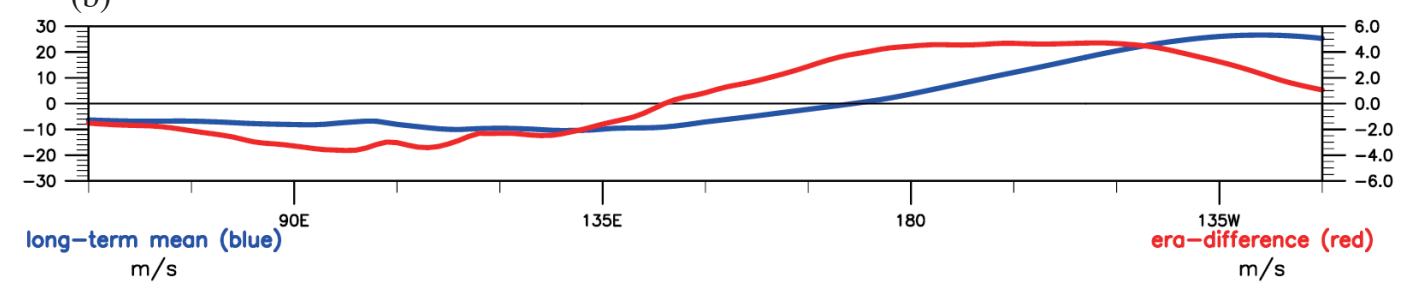

Fig. 9. Upper panel (a) is same as Fig. 8a, but averaged by different longitude, unit: $\mathrm{m}^{2} \mathrm{~s}^{-2}$. Bottom panel (b) is the symmetric $5^{\circ} \mathrm{S}-5^{\circ} \mathrm{N}$ averaged vertical wind shear (U250 - U850) in DJF. Blue line (left axis) is the long-term mean over 1979 - 2015, unit: $\mathrm{m} \mathrm{s}^{-1}$. Red line (right axis) is the eradifference, $\left(1998\right.$ - 2015) minus (1979 - 1997) to illustrate interdecadal change, unit: $\mathrm{m} \mathrm{s}^{-1}$. Positive shows the vertical westerly shear regime while negative shows the vertical easterly shear regime. 
Artificial Neural Networks (PERSIANN) can be found at https://climatedataguide.ucar.edu.

\section{REFERENCES}

Arkin, P. A. and P. J. Webster, 1985: Annual and interannual variability of tropical-extratropical interaction: An empirical study. Mon. Weather Rev., 113, 1510-1523, doi: 10.1175/1520-0493(1985)113<1510:AAIVOT $>2$. 0.CO;2. [Link]

Arnold, N. P., M. Branson, Z. Kuang, D. A. Randall, and E. Tziperman, 2015: MJO intensification with warming in the superparameterized CESM. J. Climate, 28, 2706-2724, doi: 10.1175/JCLI-D-14-00494.1. [Link]

Ashouri, H., K.-L. Hsu, S. Sorooshian, D. K. Braithwaite, K. R. Knapp, L. D. Cecil, B. R. Nelson, and O. P. Prat, 2015: PERSIANN-CDR: Daily precipitation climate data record from multisatellite observations for hydrological and climate studies. Bull.Amer. Meteorol.Soc., 96, 69-83, doi: 10.1175/BAMS-D-13-00068.1. [Link]

BBC, 2015a: AirAsia QZ8501: Plane crash blamed on weather. Available at https://www.bbc.com/news/ world-asia-30665499.

BBC, 2015b: Flight QZ8501: What we know about the AirAsia plane crash. Available at https://www.bbc. com/news/world-asia-30632735.

BBC, 2017: Thailand floods: 12 dead as record rainfall persists. Available at https://www.bbc.com/news/worldasia-38541333.

Chang, C.-W. J., W. L. Tseng, H. H. Hsu, N. Keenlyside, and B. J. Tsuang, 2015: The Madden-Julian Oscillation in a warmer world. Geophys. Res. Lett., 42, 6034-6042, doi: 10.1002/2015GL065095. [Link]

Compo, G. P., J. S. Whitaker, and P. D. Sardeshmukh, 2006: Feasibility of a 100-year reanalysis using only surface pressure data. Bull. Amer. Meteorol.Soc., 87, 175-190, doi: 10.1175/BAMS-87-2-175. [Link]

Dee, D. P., S. M. Uppala, A. J. Simmons, P. Berrisford, P. Poli, S. Kobayashi, U. Andrae, M. A. Balmaseda, G. Balsamo, P. Bauer, P. Bechtold, A. C. M. Beljaars, L. van de Berg, J. Bidlot, N. Bormann, C. Delsol, R. Dragani, M. Fuentes, A. J. Geer, L. Haimberger, S. B. Healy, H. Hersbach, E. V. Hólm, L. Isaksen, P. Kållberg, M. Köhler, M. Matricardi, A. P. McNally, B. M. Monge-Sanz, J.-J. Morcrette, B.-K. Park, C. Peubey, P. de Rosnay, C. Tavolato, J.-N. Thépaut, and F. Vitart, 2011: The ERA-Interim reanalysis: Configuration and performance of the data assimilation system. $Q$. J. Roy. Meteorol. Soc., 137, 553-597, doi: 10.1002/ qj.828. [Link]

Dias, J. and G. N. Kiladis, 2014: Influence of the basic state zonal flow on convectively coupled equatorial waves. Geophys. Res. Lett., 41, 6904-6913, doi: 10.1002/2014GL061476. [Link]
Ebita, A., S. Kobayashi, Y. Ota, M. Moriya, R. Kumabe, K. Onogi, Y. Harada, S. Yasui, K. Miyaoka, K. Takahashi, H. Kamahori, C. Kobayashi, H. Endo, M. Soma, Y. Oikawa, and T. Ishimizu, 2011: The Japanese 55year Reanalysis "JRA-55": An interim report. Sola, 7, 149-152, doi: 10.2151/sola.2011-038. [Link]

Ellingson, R. G., D. J. Yanuk, H.-T. Lee, and A. Gruber, 1989: A technique for estimating outgoing longwave radiation from HIRS radiance observations. J. Atmos. Ocean. Technol., 6, 706-711, doi: 10.1175/1520-0426(1989)006<0706:ATFEOL >2.0. CO;2. [Link]

Funk, C. C. and A. Hoell, 2015: The leading mode of observed and CMIP5 ENSO-residual sea surface temperatures and associated changes in Indo-Pacific climate. J. Climate, 28, 4309-4329, doi: 10.1175/JCLID-14-00334.1. [Link]

Harada, Y., H. Kamahori, C. Kobayashi, H. Endo, S. Kobayashi, Y. Ota, H. Onoda, K. Onogi, K. Miyaoka, and K. Takahashi, 2016: The JRA-55 Reanalysis: Representation of atmospheric circulation and climate variability. J. Meteorol. Soc. Jpn., 94, 269-302, doi: 10.2151/jmsj.2016-015. [Link]

Hayashi, Y., 1971: A generalized method of resolving disturbances into progressive and retrogressive waves by space Fourier and time cross-spectral analyses. J. Meteorol. Soc. Jpn., 49, 125-128, doi: 10.2151/ jmsj1965.49.2_125. [Link]

Hoskins, B.J. and G.-Y.Yang, 2000: The equatorial response to higher-latitude forcing. J. Atmos. Sci., 57, 11971213, doi: 10.1175/1520-0469(2000)057<1197:TERT HL>2.0.CO;2. [Link]

Hsu, H.-H. and Y.-L. Chen, 2011: Decadal to bi-decadal rainfall variation in the western Pacific: A footprint of South Pacific decadal variability? Geophys. Res. Lett., 38, doi: 10.1029/2010GL046278. [Link]

Kalnay, E., M. Kanamitsu, R. Kistler, W. Collins, D. Deaven, L. Gandin, M. Iredell, S. Saha, G. White, J. Woollen, Y. Zhu, M. Chelliah, W. Ebisuzaki, W. Higgins, J. Janowiak, K.C. Mo, C. Ropelewski, J. Wang, A. Leetmaa, R. Reynolds, R. Jenne, and D. Joseph, 1996: The NCEP/NCAR 40-year reanalysis project. Bull. Amer. Meteorol. Soc., 77, 437-472, doi: 10.1175/1520-0477(1996)077<0437:TNYRP>2.0. $\mathrm{CO} ; 2$. [Link]

Kiladis, G. N., 1998: Observations of Rossby waves linked to convection over the eastern tropical Pacific. J. Atmos. Sci., 55, 321-339, doi: 10.1175/1520-0469(1998)055<0321:OORWLT>2.0. CO;2. [Link]

Kiladis, G. N. and M. Wheeler, 1995: Horizontal and vertical structure of observed tropospheric equatorial Rossby waves. J. Geophys. Res., 100, 22981-22997, doi: 10.1029/95JD02415. [Link] 
Kiladis, G. N., G. A. Meehl, and K. M. Weickmann, 1994: Large-scale circulation associated with westerly wind bursts and deep convection over the western equatorial Pacific. J. Geophys. Res., 99, 18527-18544, doi: 10.1029/94JD01486. [Link]

Kiladis, G. N., C. D. Thorncroft, and N. M. J. Hall, 2006: Three-dimensional structure and dynamics of African easterly waves. Part I: Observations. J. Atmos. Sci., 63, 2212-2230, doi: 10.1175/JAS3741.1. [Link]

Kiladis, G. N., M. C. Wheeler, P. T. Haertel, K. H. Straub, and P. E. Roundy, 2009: Convectively coupled equatorial waves. Rev. Geophys., 47, doi: 10.1029/2008RG000266. [Link]

Kug, J.-S., F.-F. Jin, and S.-I. An, 2009: Two types of El Niño events: Cold tongue El Niño and warm pool El Niño.J. Climate, 22, 1499-1515, doi: 10.1175/2008jcli2624.1. [Link]

Lee, H.-T., 2014: Climate algorithm theoretical basis document (C-ATBD): Outgoing longwave radiation (OLR) - Daily. NOAA's Climate Data Record (CDR) Program, CDRP-ATBD-0526, 46 pp. Available at http:// www1.ncdc.noaa.gov/pub/data/sds/cdr/CDRs/Outgoing\%20Longwave\%20Radiation\%20-\%20Daily/AlgorithmDescription.pdf.

Lee, H.-T., A. Gruber, R. G. Ellingson, and I. Laszlo, 2007: Development of the HIRS outgoing longwave radiation climate dataset. J. Atmos. Ocean. Technol., 24, 2029-2047, doi: 10.1175/2007JTECHA989.1. [Link]

L'Heureux, M. L., S. Lee, and B. Lyon, 2013: Recent multidecadal strengthening of the Walker circulation across the tropical Pacific. Nat. Clim. Change, 3, 571-576, doi: 10.1038/nclimate1840. [Link]

Li, X., S.-P. Xie, S. T. Gille, and C. Yoo, 2016: Atlanticinduced pan-tropical climate change over the past three decades. Nat. Clim. Change, 6, 275-279, doi: 10.1038/ nclimate2840. [Link]

Ma, S. and T. Zhou, 2016: Robust strengthening and westward shift of the tropical Pacific Walker circulation during 1979-2012: A comparison of 7 sets of reanalysis data and 26 CMIP5 models. J. Climate, 29, 30973118, doi: 10.1175/JCLI-D-15-0398.1. [Link]

Maloney, E. D. and S. P. Xie, 2013: Sensitivity of tropical intraseasonal variability to the pattern of climate warming. J. Adv. Model. Earth Syst., 5, 32-47, doi: 10.1029/2012MS000171. [Link]

Matsuno, T., 1966: Quasi-geostrophic motions in the equatorial area. J. Meteorol. Soc. Jpn., 44, 25-43, doi: 10.2151/jmsj1965.44.1_25. [Link]

Meehl, G. A., R. Lukas, G. N. Kiladis, K. M. Weickmann, A. J. Matthews, and M. Wheeler, 2001: A conceptual framework for time and space scale interactions in the climate system. Climate Dyn., 17, 753-775, doi: 10.1007/s003820000143. [Link]

Meng, Q., M. Latif, W. Park, N. S. Keenlyside, V. A. Se- menov, and T. Martin, 2012: Twentieth century Walker Circulation change: Data analysis and model experiments. Climate Dyn., 38, 1757-1773, doi: 10.1007/ s00382-011-1047-8. [Link]

Murakami, T. and M. S. Unninayar, 1977: Atmospheric circulation during December 1970 through February 1971. Mon. Weather Rev., 105, 1024-1038, doi: 10.1175/1520-0493(1977)105<1024:ACDDTF>2.0. CO;2. [Link]

Roundy, P. E. and W. M. Frank, 2004: Applications of a multiple linear regression model to the analysis of relationships between eastward- and westward-moving intraseasonal modes. J. Atmos. Sci., 61, 3041-3048, doi: 10.1175/JAS-3349.1. [Link]

RTE, 2017: 21 dead after worst rain 'in 30 years' in southern Thailand. Available at https://www.rte.ie/ news/2017/0109/843590-thailand-floods-toll/.

Sorooshian, S., K. Hsu, D. Braithwaite, H. Ashouri, and NOAA CDR Program, 2014: NOAA Climate Data Record (CDR) of Precipitation Estimation from Remotely Sensed Information Using Artificial Neural Networks (PERSIANN-CDR), Version 1 Revision 1. NOAA National Centers for Environmental Information, doi: 10.7289/V51 V5BWQ. [Link]

Straub, K. H. and G. N. Kiladis, 2002: Observations of a convectively coupled Kelvin wave in the eastern Pacific ITCZ. J. Atmos. Sci., 59, 30-53, doi: 10.1175/1520-0469(2002)059<0030:OOACCK>2.0. CO;2. [Link]

Takayabu, Y. N. and T. Nitta, 1993: 3-5 day-period disturbances coupled with convection over the tropical Pacific Ocean. J. Meteorol. Soc. Jpn., 71, 221-246, doi: 10.2151/jmsj1965.71.2_221. [Link]

Thompson, D. M., J. E. Cole, G. T. Shen, A. W. Tudhope, and G. A. Meehl, 2015: Early twentieth-century warming linked to tropical Pacific wind strength. Nat. Geosci., 8, 117-121, doi: 10.1038/ngeo2321. [Link]

Wang, B. and X. Xie, 1996: Low-frequency equatorial waves in vertically sheared zonal flow. Part I: Stable waves. J. Atmos. Sci., 53, 449-467, doi: 10.1175/1520-0469(1996)053<0449:LFEWIV>2.0. CO;2. [Link]

Weickmann, K. and E. Berry, 2007: A synoptic-dynamic model of subseasonal atmospheric variability. Mon. Weather Rev., 135, 449-474, doi: 10.1175/ MWR3293.1. [Link]

Wheeler, M. and G. N. Kiladis, 1999: Convectively coupled equatorial waves: Analysis of clouds and temperature in the wavenumber-frequency domain. J.Atmos. Sci., 56, 374-399, doi: 10.1175/1520-0469(1999)056<0374:CC EWAO $>2.0 . \mathrm{CO} ; 2$. [Link]

Wheeler, M., G. N. Kiladis, and P. J. Webster, 2000: Largescale dynamical fields associated with convectively coupled equatorial waves. J. Atmos. Sci., 57, 613-640, 
doi: 10.1175/1520-0469(2000)057<0613:LSDFAW>2 .0.CO;2. [Link]

Xie, X. and B. Wang, 1996: Low-frequency equatorial waves in vertically sheared zonal flow. Part II: Unstable waves. J. Atmos. Sci., 53, 3589-3605, doi: 10.1175/1520-0469(1996)053<3589:LFEWIV>2.0. $\mathrm{CO} ; 2 .[\underline{\mathrm{Link}}]$

Yanai, M., S. Esbensen, and J.-H. Chu, 1973: Determination of bulk properties of tropical cloud clusters from largescale heat and moisture budgets. J. Atmos. Sci., 30,
611-627, doi: 10.1175/1520-0469(1973)030<0611:DO BPOT>2.0.CO;2. [Link]

Yang, G.-Y., B. Hoskins, and J. Slingo, 2007: Convectively coupled equatorial waves. Part III: Synthesis structures and their forcing and evolution. J. Atmos. Sci., 64, 3438-3451, doi: 10.1175/JAS4019.1. [Link]

Zhang, C. and P. J. Webster, 1989: Effects of zonal flows on equatorially trapped waves. J. Atmos. Sci., 46, 36323652, doi: 10.1175/1520-0469(1989)046<3632:EOZF OE $>2.0 . C O ; 2$. [Link] 